\title{
CLINICAL AND LABORATORY EVALUATION OF THE EFFECTIVENESS OF THE APPLICATION OF NONSTEROID ANTI-INFLAMMATORY PREPARATION OF THE COXIB GROUP
}

Article history:

Submitted 4 April 2019

Accepted 27 June 2019

\section{Anastasiya Gvozdeva², Andrej Panin'2, Elena Gershtein ${ }^{1}$, Aleksandr Tsitsiashvili ${ }^{2 *}$, Nikolaj Kushlinsky',}

\author{
${ }^{1}$ Department of Clinical Biochemistry and Laboratory Diagnostics, \\ Moscow State University of Medicine and Dentistry \\ named after A.I. Evdokimov, Moscow, Russia \\ ${ }^{2}$ Department of Surgical Dentistry, Moscow State University of Medicine \\ and Dentistry named after A.I. Evdokimov, Moscow, Russia
}

"Corresponding Author:amc777@yandex.ru

\section{INTRODUCTION}

Most surgical dental procedures in the pre- and postoperative periods are accompanied by pain sensations of greater or lesser intensity, so pain control is one of the most urgent problems of dentistry [3]. The presence of pain significantly reduces the quality of life, ability to work and social activity of patients. Pain that occurs in the maxillofacial region is most often associated with the development of the inflammatory process, both infectious and traumatic origin. Effective pain therapy should include a clear understanding of the mechanisms of its development, as well as the integrated use of medication that affect the main links of pathogenesis.

There are several groups of drugs used for pain relief. The most common group of drugs for this purpose is a group of non-steroidal anti-inflammatory drugs $[4,5]$. They have anti-inflammatory, analgesic, antiplatelet and antipyretic effects.

A common element of the mechanism of action of NSAIDs is the inhibition of the synthesis of prostaglandins (PG) from arachidonic acid by inhibiting the cyclooxygenase enzyme (COX) [2]. By the ability to predominantly inhibit COX-1 or COX-2, NSAIDs of three groups are isolated: non-selective, inhibiting the activity of both enzymes; NSAIDs, predominantly suppressing COX-2 and having a weaker effect on COX-1; selective for COX-2, which almost do not have effect on COX-1. According to a number of authors, among all appointments in surgical practice, more than $70 \%$ fall to non-selective NSAIDs (ketoprofen, ketorolac, ibuprofen) that have activity against both cyclooxygenase-1 and cyclooxygenase- 2 .

The main negative property of all NSAIDs is the high risk of the development of undesirable reactions from the gastrointestinal tract (GIT) [17]. At present, a specific syndrome, NSAID-gastroduodenopathy, has even been isolated [5]. The expansion of the range of drugs for the treatment of pain syndrome facilitates the choice of drugs based on the point of application and the mechanism of their action. A pressing issue is the objective assessment of the degree of inflammatory response and assessment of the dynamics of anti-inflammatory therapy conducted, as well as the introduction of new, modern drugs into surgical dentistry $[1,9]$. To reduce the effects of NSAIDs on the mucous membrane of the gastrointestinal tract, a new highly selective drug Etoricoxib (Arcoxia) was developed. Arcoxia is a selective inhibitor of COX-2 with pronounced analgesic and anti-inflammatory action, has a rapid onset of action and prolonged relief of pain $[10,19]$. The inflammatory response is a universal protective and adaptive response to exposure to exogenous and endogenous damaging factors, including in the surgical area $[14,18]$.

Biologically active substances such as histamine, interleukins (IL), products of arachidonic acid metabolism provide stimulation of the inflammatory reaction. The basis of the pathogenesis of tissue damage is the launch of the cytokine cascade, which includes, on the one hand, pro-inflammatory cytokines, and on the other, anti-inflammatory mediators. Hyperproduction of cytokines leads to the development of a systemic inflammatory response and may cause the development of a number of pathological conditions, in particular, septic shock. A balance of pro- and antiinflammatory cytokine production is a prerequisite for maintaining perioperative immune homeostasis. Some studies have also shown that in the development and maintenance of chronic inflammation in periodontal tissues, increased production of matrix metalloproteinases (MMPs) is important - groups of enzymes that are produced by different cells and microorganisms of 
the oral cavity, participate in the mechanisms of the immune response, break down most- proteins of the extracellular matrix and the basement membrane $[6$, $7,11-13,15,16]$. Under the conditions of the disease, MMPs are involved in the degradation and processing of a variety of growth factors, cytokines and substances involved in apoptosis, cell adhesion and, together with other extracellular proteinases, can cause irreversible damage to tissues [20-26]. In this regard, the study of the level of MMP and related growth factors and proinflammatory cytokines could be an additional criterion for evaluating the effectiveness of NSAIDs, taking into account the point of application and the mechanism of their action.

\section{The aim}

of the study is to substantiate the anti-inflammatory effect of Etoricoxib based on the study of the dynamics of IL-6, MMP-2, MMP-8 and vascular endothelium growth factor (VEGF) in the oral fluid of patients during surgical dental procedures.

\section{MATERIALS \\ AND RESEARCH METHODS}

The study included 28 patients ( 12 men and 16 women) aged from 20 to 35 years who underwent examination and treatment at the Moscow State University of Medicine and Dentistry named after. A.I. Evdokimov of the Ministry of Health of Russia at the Department of Surgical Dentistry with a diagnosis of dental retention (K01.0), dystopia of the teeth (K07.3). Patients were divided into groups as follows:

The study group: 11 patients without somatic pathology, not undergoing treatment with the use of drugs, with no pathology on the part of periodontal tissues; they underwent planned surgical manipulations (removal of third molars) with the appointment of local antiseptic therapy and etoricoxib $90 \mathrm{mg}$ according to the following scheme: 1 tablet per day 2 days before surgery, 1 tablet per day of surgery and subsequent days if there is pain 1 tablet per day.

Control group: 17 people - conditionally healthy patients with healthy oral cavity who did not undergo surgical interventions.

Before treatment, all patients underwent a comprehensive examination, which consisted of a survey, clarification of complaints, collecting a history of illness and anamnesis of life, finding out the presence of concomitant general somatic pathology and the fact of taking medications. Further, skin and visible mucous membranes, face configurations, and palpation of regional lymph nodes were evaluated, and then the oral cavity was examined. The degree of mouth opening, the state of the mucous membrane of the vestibule and the oral cavity itself was evaluated. All the teeth were examined. Particular attention was paid to the state of periodontal tissues. Patients with the presence of clinically severe pathology of periodontal tissues (gingivitis and acute periodontitis) were excluded from the study group. All patients had no contraindications for taking Etorikoksib, which was confirmed by examination by a general practitioner. All patients signed voluntary informed consent.

Clinical evaluation of the local inflammatory process was performed on days $1,3,5$, and 7 after the operation, based on the degree of edema and hyperemia of the postoperative mucosa, as well as the subjective assessment of patient pain by an 11-point digital rating scale of pain intensity, which consists of 11 points from 0 no pain to 10 pain that cannot be tolerated. (Visual analogue scale of pain, VAS).

46 samples of unstimulated saliva were tested. In the study group, markers were determined according to the following scheme: first collection -2 days before surgery, then patients were prescribed etoricoxib $90 \mathrm{mg}, 1$ tablet per day, second collection - on the day of surgery (before the manipulation), third collection -7 days after the manipulation. Most patients received etoricoxib for 2 days after surgery. In the control group, a single collection of mixed saliva was performed.

Methods of collecting saliva: the collection was carried out in the morning, on an empty stomach in $1^{\text {st }}$ and $3^{\text {rd }}$ collection and after at least $2^{\text {nd }}$ hours in the second collection, in graduated tubes. Before the procedure, the patient rinsed his mouth with distilled water for 30 seconds, followed by 5 minutes of rest. Then the patient swallowed all the accumulated saliva, after which the direct collection of material began for 15 minutes. At the end, the tube was tightly closed with a lid, placed in a container with ice and delivered to the laboratory for one and a half hours. In the laboratory, the tubes were centrifuged at a speed of $3000 \mathrm{rpm}$ for 10 minutes at $4^{\circ} \mathrm{C}$, after which the saliva was frozen and stored at $-80^{\circ} \mathrm{C}$ until the test. Concentrations of MMP-2, MMP-8, IL-6 and VEGF were determined using Human MMP-2 (total), Human MMP-8 (total), Human IL-6 and Human VEGF (Quantikine', R \& D Systems, USA) in accordance with the manufacturer's instructions. Before starting the determination, saliva samples stored at $-80^{\circ} \mathrm{C}$ were thawed at room temperature, centrifuged at 10,000 rpm for 2 minutes, and diluted 100 times with standard diluent solution included in the kit. The measurements were performed on a BEP 2000 Advance automatic immunoassay analyzer (Siemens Healthcare Diagnostics, Germany). The contents of MMP-8 and MMP-2 were expressed in nanograms (ng), IL-6 and VEGF - in picograms (pg) 
per $1 \mathrm{ml}$ of saliva. The obtained data was processed using the program "Statistica 7.0". When comparing indicators and analyzing their interrelationships, the non-parametric criteria of Mann-Whitney, KruskelWallis, Wilokson pair test, Friedman ANOVA were used. Differences and correlations were considered significant at $\mathrm{p}<0.05$.

\section{RESULTS AND DISCUSSION}

The initial content of MMP-2 and VEGF in the saliva of patients who then underwent surgery and who received Etoricoxib at a dose of $90 \mathrm{mg}$ was significantly lower than in the control group (Table 1). The reduction in MMP-8 and IL-6 levels was not statistically significant.

Table 1. Content of MMP-2, MMP-8, LL-6 and VEGF in mixed saliva of patients who received $90 \mathrm{mg}$ of etoricoxib before and after surgery, and the control group

\begin{tabular}{|c|c|c|c|c|c|c|}
\hline \multicolumn{2}{|l|}{ Group } & $\mathrm{N}$ & MMP-2 & MMP-8 & IL-6 & VEGF \\
\hline \multicolumn{2}{|c|}{ Control } & 17 & $\begin{array}{l}17,0 \\
14,5-18,6\end{array}$ & $\begin{array}{l}143 \\
96-278\end{array}$ & $\begin{array}{l}7,7 \\
3,8-11,5\end{array}$ & $\begin{array}{l}2899 \\
1924-3338\end{array}$ \\
\hline \multirow{3}{*}{ 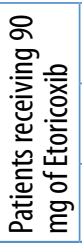 } & Visit 1 & 11 & $\begin{array}{l}12,01 \\
10,1-13,3\end{array}$ & $\begin{array}{l}110 \\
66,2-194\end{array}$ & $\begin{array}{l}5,4 \\
1,6-9,4\end{array}$ & $\begin{array}{l}16421 \\
1352-2510\end{array}$ \\
\hline & Visit 2 & 10 & $\begin{array}{l}13,9 \\
11,4-17,0\end{array}$ & $\begin{array}{l}133 \\
40,8-278\end{array}$ & $\begin{array}{l}13,4 \\
3,5-17,8\end{array}$ & $\begin{array}{l}14971 \\
1147-1859\end{array}$ \\
\hline & Visit 3 & 8 & $\begin{array}{l}14,21 \\
12,5-15,7\end{array}$ & \begin{tabular}{|l|}
111 \\
$68,4-142$
\end{tabular} & \begin{tabular}{|l|}
23,61 \\
$13,9-67,1$
\end{tabular} & \begin{tabular}{|l|}
18461 \\
$1454-2249$
\end{tabular} \\
\hline
\end{tabular}

* _ Indicators of median, lower and upper quartile are presented (25-75\%); $1 p<001$ with respect to control

In the postoperative period, the levels of MMP-2, MMP-8 and VEGF did not significantly change, and the level of IL- 6 significantly increased $(\mathrm{p}=0.011$ by Friedman ANOVA test) from 5.4 to $23.6 \mathrm{pg} / \mathrm{ml}$ by median.

As clearly shown in the graphs, in most patients, the level of MMP-2 (Fig. 1) increased immediately before the operation while receiving etoricoxib (visit 2) and returned to the initial level 7 days after it (visit 3). The level of MMP-8 changed in different directions (Fig. 2): it increased in 6 and decreased in 5 patients. VEGF level slightly decreased or remained almost unchanged (Fig. 3), whereas IL-6 increased significantly after taking etoricoxib before the operation and continued to increase a week after it in all examined patients (Fig. 4).

Pain syndrome was observed only in 2 out of 11 patients of the studied group. Significant differences in the initial levels of markers, as well as the dynamics of their changes on the background of the drug intake and surgical intervention in these patients, have not been found from the indicators of patients without a pronounced pain syndrome. Thus, during reception of the non-steroidal anti-inflammatory drug etoricoxib at a dose of $90 \mathrm{mg}$, all patients experience an increase in the level of the pro-inflammatory cytokine IL-6 in unstimulated saliva, which lasts a week after the surgery 5-6 days after stopping the drug. Changes in the levels associated with inflammatory processes in paradont MMP-8 and MMP-2, as well as the stimulator of neoangiogenesis VEGF has a multidirectional nature, not associated with the presence of pain and the effect of treatment.

In the studied group, edema and hyperemia of the mucous membrane of the postoperative region in $87 \%$ of cases were expressed on the second and third days after surgery, on the fifth day their decrease was noted at $92 \%$, on the seventh day the absence of edema was $100 \% .98 \%$ of patients in study group noted the absence of pronounced pain syndrome and the absence of the need to take NSAIDs after the intervention, $73 \%$ of patients in subgroup 2 of the study group stopped taking Etoricoxib $90 \mathrm{mg}$ on the third day after the intervention, noting the absence of pain, which can indicate the presence of a cumulative effect when taking the drug.

Clinical results showed intense regression of signs of local inflammation, such as edema and hyperemia of the mucous membrane of the post-operating area, as well as a marked reduction in pain sensitivity in patients of study group, which indicates a high anti-inflammatory and analgesic activity of the drug etoricoksib $90 \mathrm{mg}$.

When studying the levels of proinflammatory cytokines, matrix metalloproteinases and vascular endothelial growth factor in the mixed saliva of patients, adequate dynamics of these factors was established when prescribing Etoricoxib $90 \mathrm{mg}$ in patients during surgical dental surgery, but generally reflecting the pharmacokinetics and pharmacodynamics of Etoricoxib drug.

As a result of the study, a drug Etoricoxib $90 \mathrm{mg}$ revealed pronounced analgesic and anti-inflammatory activity during outpatient surgical interventions. In all cases, patients noted the absence of pain in the postoperative period for 3 days (after 4 days of taking the drug).

\section{REFERENCES}

1. Atrushkevich V.G, Pikhlak U.A. Efficacy and safety of non-rodent anti-inflammatory drugs Ketorol and Nise in parodontologic practice // Clinical Dentistry. - 2005. - № 1. - p. 34-36. 


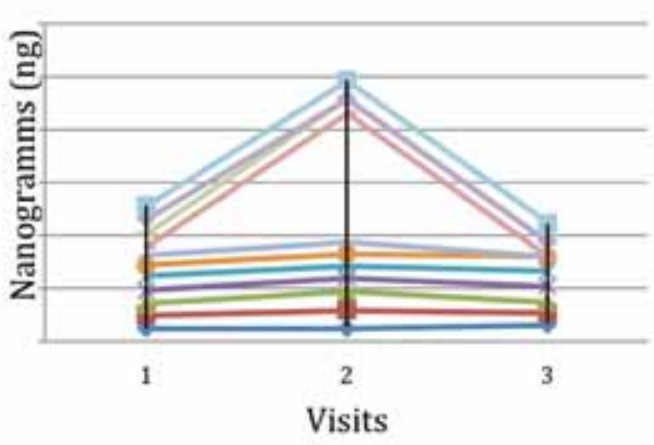

Fig. 1. Dynamics of the content of MMP-2 in the saliva of individual patients

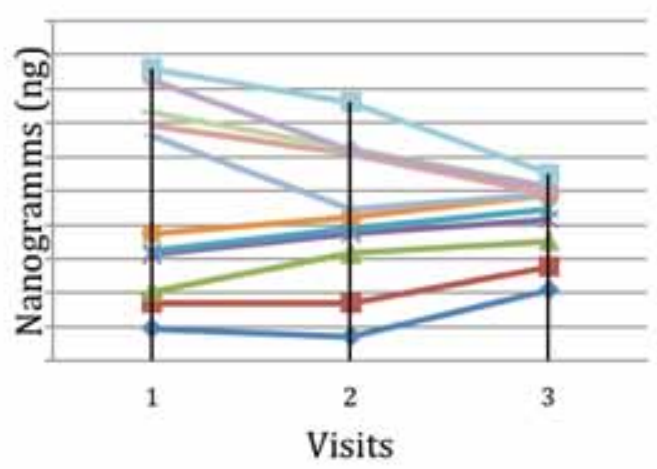

Fig. 2. Dynamics of the content of MMP-8 in the saliva of individual patients

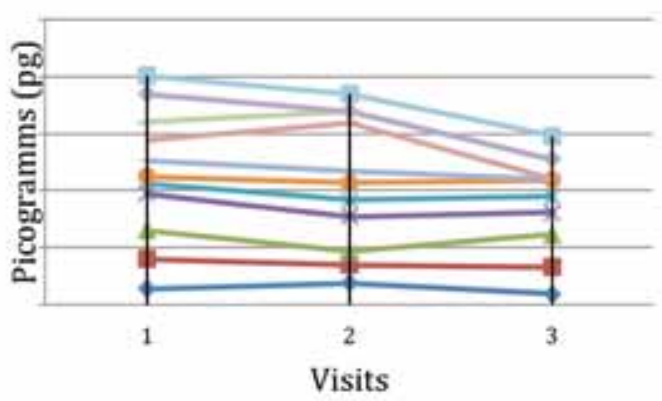

Fig.3. Dynamics of the content of VEGF in the saliva of individual patients

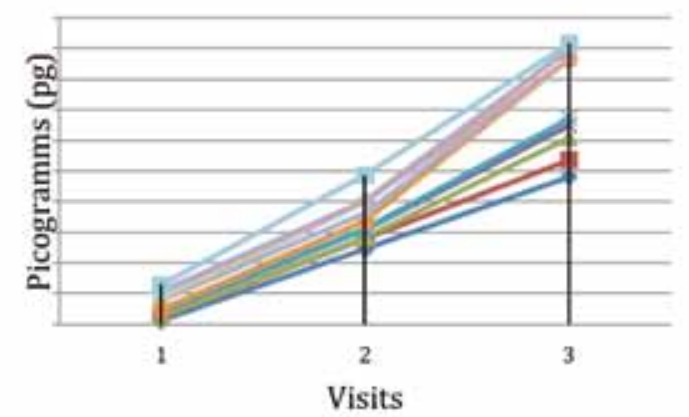

Fig. 4. Dynamics of the content of IL-6 in the saliva of individual patients
2. BADOKIN V.V. Selective cyclooxygenase inhibitors in the treatment of osteoarthritis. // Consilium medicum. - 2010. - №10. - p. 3-6.

3. Zoryan E. V., Rabinovich S. A. The individual choice of NSAIDs from stomatological practice // Dentist practice No. 3. - 2015. - №7 (257). - p. 3-6.

4. Pakhomova IG, Pavlova E. Yu. Non-steroidal antiinflammatory drugs: focus on safety when choosing a drug. // Consilium medicum "Neurology / rheumatology". - 2014. - №1. - p. 30-34.

5. EvSEEV MA. NSAID-induced gastroduodenal ulcers, complicated by bleeding. Russian medical journal. 2006; (15): 1099-107.

6. Kushlinsky N.E., SOlOVYKH E.A., KaraOglanova TB, Bayar U., Gershtein E.S., Troshin A.A., Kostyleva O.I., Grinin V.M., MaKsiMOVSKaYa L.N. ., YaNUSHEVICH O.O. The content of matrix metalloproteinases of the $8^{\text {th }}$ and $9^{\text {th }}$ type in the oral fluid of patients with chronic generalized periodontitis. Bull exp. biol. med., 2011, t. 152, № 8, p.201-206.

7. Kushlinsky N.E., SOlOVykH E.A., KaraOglanova TB, Bayar U., Gershtein E.S., Troshin A.A., Maksimovskaya L.N., YanUSheViCH O.O. Matrix metalloproteinases and inflammatory cytokines in the oral fluid of patients with chronic generalized periodontitis with various structural materials. Bull exp. biol. medical, 2012, V. 153, № 1, pp. 82-87.

8. Ovechrin A. M. Non-steroidal anti-inflammatory drugs in anesthesiology and surgery // Regional anesthesia and treatment of acute pain. - 2009. - V. 3, N. 2. - P. 5-14.

9. Pavlenko A.V., Volosovets T.N. Modern approaches to the control of pain syndrome in dentistry // Modern dentistry. - 2003. - № 1. - p. 6-9.

10. Karateev AE, Nasonov EL, Yakhno NN. Clinical recommendations "Rational use of nonsteroidal anti-inflammatory drugs (NSAIDs) in clinical practice." Modern rheumatology. 2015; 9 (1): 4-23.

11. Alfant B., Shaddox L.M., Serdar M. Matrix metalloproteinase levels in children with aggressive periodontitis // J. Periodontol.-2008. - Vol.79, N.5. p. 819-826.

12. Andonovska B., Dimova C., Panov S. Matrix metalloproteinases (MMP-1, -8, -13) in chronic periapical lesions // Vojnosanit Pregl. - 2008. - Vol.65, N.12. - p. 882-886.

13. Beklen A., Ainola M., Hukkanen M., Gurgan C., Sorsa T., KontTinen Y.T. MMPs, IL-1, and TNF are regulated by IL-17 in periodontitis // J. Dent. Res. - 2007. - Vol.86, N.4. - p. 347-351.

14. Brown D., Stephen E., Donald P. Evaluation of Multiday Analgesia With Etoricoxib in a Doubleblind, Randomized Controlled Trial Using the Postoperative Third-molar Extraction Dental Pain Model. // Clinical Journal of Pain. - 2013. - №6. - C. 492-498. doi: 10.1097/AJP.0b013e318260c144. 
15. Costa, P. P., ET AL. (2010). "Salivary interleukin-6, matrix metalloproteinase-8, and osteoprotegerin in patients with periodontitis and diabetes." J Periodontol 81(3): 384-391.

16. Gorska R., Nedzi-Gora M. The effects of the initial treatment phase and of adjunctive low-dose doxycycline therapy on clinical parameters and MMP8, MMP-9, and TIMP-1 levels in the saliva and peripheral blood of patients with chronic periodontitis // Arch. Immunol. Ther. Exp. (Warsz). - 2006. - Vol.54, N.6. - p. 419-426.

17. Jafar W, Jafar AJN, Sharma A. Upper gastrointestinal haemorrhage: an update. Frontline Gastroenterol. 2016 Jan; $7(1): 32-40$.

18. Manal A. Among Patients Undergoing Third Molar Extraction, Amoxicillin Administration Preoperatively or Postoperatively is Likely to be More Efficacious Than Placebo in Preventing Postoperative Complications. //Journal of Evidence-Based Dental Practice. 2012. - №12. - P. 149-150.

19. Smith S.R., Deshpande B.R., Collins J.E., et AL. Comparative pain reduction of oral non-steroidal anti-inflammatory drugs and opioids for knee osteoarthritis: systematic analytic review. Osteoarthritis Cartilage. 2016 Jun;24(6):962-72. doi: 10.1016/j. joca.2016.01.

20. Bykov I.M., IvCHENKo L.G., DOMENYUK D.A., Kostyukova N.Y., Storozhuk A.P., Ilijev D.M. Salivary the level of proinflammatory cytokines in children with autoimmune diabetes mellitus in different phases of compensation endocrinopathy. Kuban Scientific Medical Bulletin. 2017; 24(4): 39-48. (In Russ., English abstract). DOI: 10.25207/1608-62282017-24-4-39-48.

21. Davydov B.N., Gilmiyarova F.N., Domenyuk D.A., IvChenko L.G. Clinical and diagnostic significance of the activity of matrix metalloproteinase and their tissue inhibitors in assessing the condition of periodontal tissues in children with type 1 diabetes mellitus. Part I. Children's dentistry and prevention. 2017; Vol. XVI; 4 (63): 14-19. (In Russ.).

22. Davydov B.N., Gilmiyarova F.N., Domenyuk D.A., IvCHENKo L.G. Clinical and diagnostic significance of the activity of matrix metalloproteinase and their tissue inhibitors in assessing the condition of periodontal tissues in children with type 1 diabetes mellitus. Part II. Children's dentistry and prevention. 2018; Vol. XVII; 1 (64): 37-46. (In Russ.).

23. IVChenko L.G., Domenyuk D.A. Diagnosis of immunometabolic disorders in children with type I diabetes mellitus. Kuban Scientific Medical Bulletin. 2017; 1(2): 73-82. (In Russ., English abstract). DOI:10.25207/1608-6228-2017-2-73-82.

24. Gilmiyarova F.N., Davydov B.N., Domenyuk D.A., IVCHENKo L.G. Influence of severity of type I diabetes mellitus in children on dental status and immunological, biochemical parameters of blood serum and oral fluid. Part I. Periodontology. 2017; Vol. XXII; 2 (83): 53-60. (In Russ.).
25. Gilmiyarova F.N., Davydov B.N., Domenyuk D.A., IVCHENKO L.G. Influence of severity of type I diabetes mellitus in children on dental status and immunological, biochemical parameters of blood serum and oral fluid. Part II. Periodontology. 2017; Vol. XXII; 3 (84): 36-41. (In Russ.).

26. Domenyuk D.A., Porfyriadis M.P., BudayCHIEv G. M-A. Contemporary methodological approaches to diagnosing bone tissue disturbances in children with type i diabetes. Archiv EuroMedica, 2018; 8(2): 71-81. https://doi.org/10.35630/2199$885 \mathrm{X} / 2018 / 8 / 2 / 71$ 